\title{
Kinetics and Mechanism of Bulk Polymerization of Vinyl Chloride in a Polymerization Reactor
}

\author{
A. S. Ibrahim*, Y. A. Ali, H. M. Saad and I. H. Amur \\ Chemical Engineering Department, Dhofar University, Sultanate of Oman
}

Received 1 March 2015; Accepted 4 May 2015

\begin{abstract}
Polyvinyl chloride (PVC) is the third most commonly produced polymer and is important because of its mechanical characteristics. The most common method of PVC manufacturing is the process of suspension. Although, there are several benefits associated with suspension, this study will focus on the bulk polymerization of vinyl chloride; highlight the physical and chemical properties of PVC, which can be changed through an estimation of the optimum ratio that exists between the hydrophilic and hydrophobic parts of the polymer's surface, and propose a new mathematical model which will be helpful for the conversion of PVC into a useful form. The result will be the proposal of a new dynamic mathematical model for the three-phase structure model. All particles have been taken into account in the proposed model, which helped contribute to the reaction in gel, solid, and liquid phases, emphasizing the use of mercury $(\mathrm{Hg})$ as a catalyst. The proposed mathematical model considers the heat and mass transfer between the liquid, gel, and solid phases with chemical reactions that occur between the liquid and solid phases, and between the gel and solid phases. The effect of the catalyst and volumetric flow rates of vinyl chloride monomer (VCM) on the system have been evaluated through the proposed mathematical model. Furthermore, the study's experimental data have been compared with the findings of the suggested model in the context of concentration and temperature reaction. Obtained results show good agreement between the proposed mathematical model and the actual plant data.
\end{abstract}

Keywords: Mathematical model, Catalyst, Polymerization reactor, Chemical reaction, Heat and mass transfer.

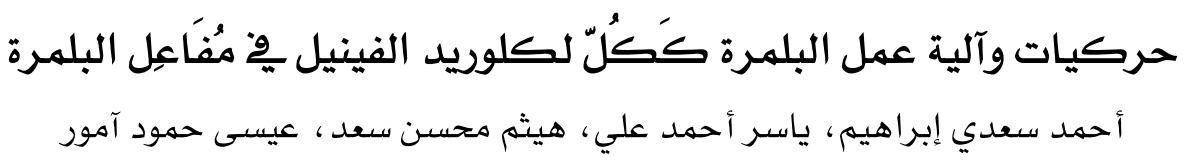

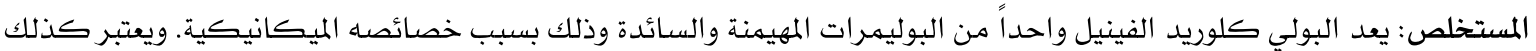

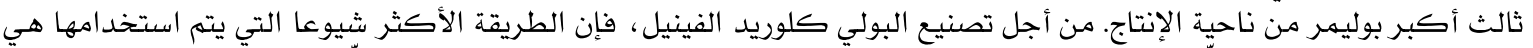

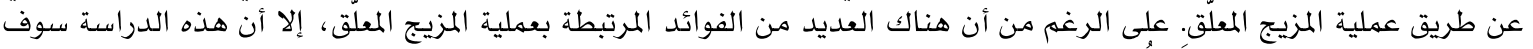

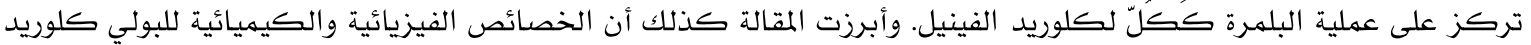

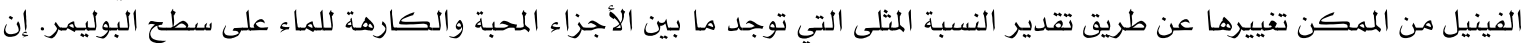

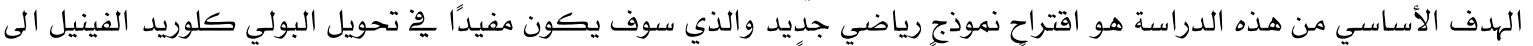

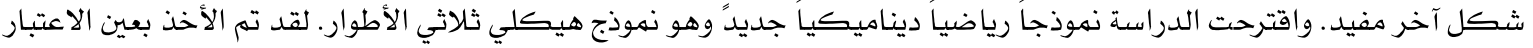

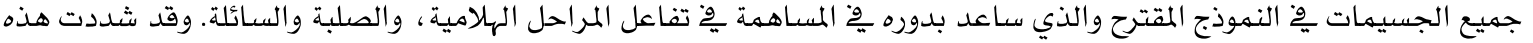

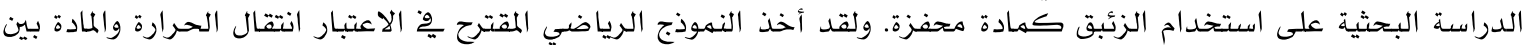

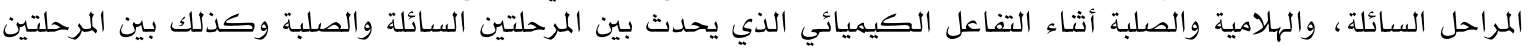

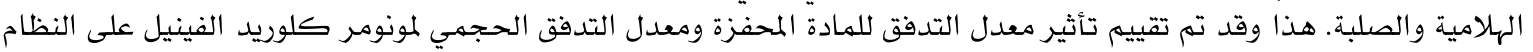

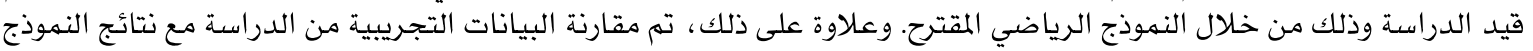

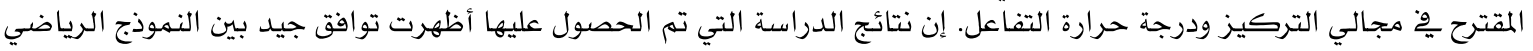
المقترح وبيانات المصنع الفعلية.

الكلمات المفتاحية : نموذج رياضي، مادة محفزة، مفاعل البلمرة، تقاعل كيميائي، انتقال الحرارة والمادة

Corresponding author's e-mail: ahmadsaadi@gmail.com 


\section{Nomenclature}

\begin{tabular}{|c|c|}
\hline Symbol & Definition, Unit \\
\hline A & Cross-sectional area of the reactor, $\left(\mathrm{m}^{2}\right)$ \\
\hline $\mathrm{C}_{\mathrm{Ai}}$ & Concentration of vinyl chloride monomer, $\mathrm{mol} / \mathrm{m}^{3}$ \\
\hline $\mathrm{C}_{\mathrm{Ao}}$ & Concentration of poly vinyl chloride, $\mathrm{mol} / \mathrm{m}^{3}$ \\
\hline $\mathrm{C}_{\mathrm{Ag}}$ & Concentration of gel phase, $\mathrm{mol} / \mathrm{m}^{3}$ \\
\hline $\mathrm{C}_{\mathrm{p}}$ & Heat capacity, $\mathrm{Kj} / \mathrm{mol} . \mathrm{k}$ \\
\hline $\mathrm{M}_{\mathrm{Ai}}$ & Mass rate of vinyl chloride monomer, $\mathrm{mol} / \mathrm{sec}$ \\
\hline $\mathrm{mw}_{\mathrm{cat}}$ & Catalyst molecular weight, $\mathrm{kg} / \mathrm{mol}$ \\
\hline $\mathrm{mw}_{\mathrm{Ai}}$ & Molecular weight of VCM, kg/mol \\
\hline $\mathrm{k}_{\mathrm{lg}}$ & Mass transfer coefficient from liquid to gel phases, $1 / \mathrm{sec}$ \\
\hline $\mathrm{k}_{\mathrm{gs}}$ & Mass transfer coefficient from gel to solid phases, $1 / \mathrm{sec}$ \\
\hline$\Delta \mathrm{H}_{\mathrm{r}}$ & Heat enthalpy of reaction, $\mathrm{Kj} / \mathrm{mol} . \mathrm{k}$ \\
\hline $\mathrm{F}_{\mathrm{Ai}}$ & Volumetric flow rate, $\mathrm{m}^{3} / \mathrm{s}$ \\
\hline $\mathrm{u}_{\mathrm{b}}$ & Bubble gas velocity, $\mathrm{m} / \mathrm{s}$ \\
\hline $\mathrm{T}_{\mathrm{i}}$ & Feed temperature, $\mathrm{k}$ \\
\hline $\mathrm{T}_{\mathrm{g}}$ & Temperature of gel phase, $\mathrm{k}$ \\
\hline $\mathrm{r}_{\mathrm{a}}$ & Overall rate of reaction, $\mathrm{mol} / \mathrm{kg}$ cat. $\mathrm{m}^{2}$ \\
\hline$\rho_{\text {cat }}$ & Catalyst density, $\mathrm{kg} / \mathrm{m}^{3}$ \\
\hline $\mathrm{T}_{\mathrm{o}}$ & Temperature of reaction, $\mathrm{k}$ \\
\hline $\mathrm{V}$ & Volume of reactor, $\mathrm{m}^{3}$ \\
\hline $\mathrm{t}$ & Time, sec \\
\hline Cat & Catalyst \\
\hline $\mathrm{k}_{\mathrm{i}}$ & Rate of activation \\
\hline $\mathrm{k}_{\mathrm{in}}$ & Rate of initiation \\
\hline $\mathrm{k}_{\mathrm{p}}$ & Rate of propagation \\
\hline $\mathrm{k}_{\text {liv }}$ & Rate of live polymer \\
\hline $\mathrm{k}_{\text {dead }}$ & Rate of dead polymer \\
\hline
\end{tabular}




\section{Introduction}

Polyvinyl chloride (PVC) is considered one of the most versatile polymers due to its mechanical properties and is the third most frequently produced polymer. In 2014, the quantity of PVC produced reached more than $50,000,000$ tons because of its wide demand in different fields. Furthermore, the production of PVC is expected to increase in upcoming years due to its significant and effective performance in different fields. According to Ambrozek et al. (2012), appropriate and suitable techniques must be adopted for the conversion of PVC into a usable, practical form. A study by Lăzăroaie et al. (2010) established that PVC can be generated commercially through different approaches and techniques, including suspension emulsion, solution polymerization, and bulk processing. According to Ibrahem (2012), the process of suspension is one of the most widelyused techniques for PVC manufacturing because an emission technique is used for the production of almost $12 \%$ of PVC. Additionally, $80 \%$ of PVC is manufactured with the help of polymerization, $7.5 \%$ is manufactured through the emulsion process, and $0.5 \%$ is manufactured by solution. Among all of these processes and approaches, the process of suspension has been found to be the most common and effective approach due to the fact that the suspension process provides the advantage of inexpensive dying and enables inexpressive separation of resin. Additionally, the suspension process also helps in providing strong control over the entire manufacturing process.

Besides focusing on the advantages of the suspension process, this paper will emphasize the bulk process of the polymerization of vinyl chloride. Kamo et al. (2012) stated that polymerization of monomers is carried out without the need of diluents in the bulk process. The research further asserted that one of the major benefits associated with the bulk process is polymer fabrication. It has been ascertained that fabricated polymers do not contain any impurities. On the other hand, Lathia et al. (2004) identified a number of disadvantages associated with the bulk process, including limited and/or inadequate control of excessive removal of heat and rate of reaction. In this regard, (Blazevska and Spasesk 2010) proposed a mathematical model which can be used for predicting the best possible range of temperaturebetween $40-70^{\circ} \mathrm{C}$ for a PVC polymerization system. The proposed mathematical model was dependent on the ratio of the mass transfer coefficient between liquid and gel phases.
An evaluation of the research by Balakrishnam et al. (2005) revealed that the analysis and study of reaction conditions is highly significant due to the fact that it assists in directing the pressure, catalyst flow rate, and temperature effects. All of these actions play a major and effective role in ensuring the reduction of the effects of pollution within the environment. A number of studies have sought to analyze and examine thermal properties of PVC in normal environmental conditions. In order to carry out such analyses, the research mathematical model systems were employed. Chavadej et al. (2008) developed an integrated and comprehensive mathematical model so as to examine the properties and behaviors of industrial PVC. Chattopadhyay and Madras (2002) documented a number of studies to assess different characteristics of PVC, including its stability, degradation rates, and modification surfaces of PVC for several applications in medical research (Blazevska-Gilev and Spasesk 2010; Chattopadhyay and Madras 2002; Cohan 1975; Ibrahem 2012; Kamo et al. 2012; Maezawa et al. 2004; Scott et al. 1990).

Zuga and Cincu (2006) stated that the physical and chemical properties of PVC can be altered by carrying out calculations on the optimum ratio between the hydrophilic and hydrophobic parts of a polymer's surface. According to (Blazevska and Spasesk 2010), this calculation can assist in converting PVC into a valuable and utilizable form and can be deployed in several different applications. It seems necessary to discern whether the scaled-up pilot plan has been deployed so as to carry out the comparison of simulation results obtained through experimental study. It also appears essential that the modeling of PVC's adsorption systems must be taken into account. Such modeling and comparison will help in assessing the effects of the catalyst flow rate on the reaction's temperature; specifically, the impact of potassium/titanium oxide $\left(\mathrm{Pt} / \mathrm{TiO}_{2}\right)$ must be analyzed. In addition to this, it would also help in determining the variation in the concentration of emulsion reactants with the passage of time (Blazevska and Spasesk 2010; Field 1973; Kiparissides et al. 1994; Zuga and Cincu 2006).

The current research will elaborate a newly proposed mathematical model which will be useful for the transformation of PVC into a utilizable form. The study further seeks to determine whether the established mathematical model can be applied to gel, liquid, and solid phases so as to carry out comparisons between the experimental results. Despite the mathematical model, this study intends to carry out a simulation so as to evaluate as well as 
examine the flow rate of a vinylchloride monomer (VCM). Additionally, a consideration of simulation results will also help in identifying the impact of a catalyst's flow rate on reaction temperature and concentration (Chattopadhyay and Madras 2002; Cohan 1975; Field 1973; Ibrahem 2012; Kamo et al. 2012). In addition to this, the descriptive behavior of the newly proposed mathematical model for PVC in a continuous stirred tank reactor (CSTR) will also be highlighted in this study.

\section{Proposed Descriptive Behavior of the New Mathematical Model for the PVC CSTR Process}

In this account, several assumptions will be taken into account in order to assure the integrity and reliability of the process [Table 1]. VCM will be mixed with water in order to run the experiment, which will be carried out by allowing the entry of a mixture reactant from the top of the CSTR. The reaction will be accomplished in the liquid phase by allowing the catalyst, $\mathrm{Hg}$, to flow down within the reactor. This process will be carried out with the help of five major mechanisms: initiation, rates of activation, propagation, a living polymer transfer. and the death of a polymer chain. A chemical reaction will be activated between the reactants and the $\mathrm{Hg}$ catalyst in the liquid phase. However, almost $70-90 \%$ of the conversion of VCM is generally in the solid phase, while $\sim 10-30 \%$ is transferred in the gel phase. Afterwards, the VCM will be converted into the product of the PVC solid phase (Ambrozek et al. 2012; Balakrishnan et al. 2005; Chattopadhyay and Madras 2002; Field 1973). This proposed model accounts for the effects of all of the most important variables in the system [Fig. 1]. Subsequently, the product will flow down into the VCM which is not converted. Catalyst liquid and PVC solid phases then will he separated from the bottom of the CSTR.

\section{Assumptions of the Modified Mathematical Model}

It is essential that several different assumptions are taken into account when modifying the mathematical model as these assumptions will help in assessing the credibility and reliability of the final findings. In light of this, it has been presumed that CSTR includes the gel, solid, and liquid phases. Also assumed is that reactions occur with catalysts during the liquid phrase (Kiparissides et al. 1994). In addition to this, it is also observed and identified in the new mathematical model that all three phases take place in controlled conditions.

There are several assumptions which need to be taken into account and include minor and insignificant temperature and concentration gradients within the CSTR. The altered mathematical model also takes into consideration the possibility that the liquid phase is not comprised of two main elements-VM or $\mathrm{Hg}$. The study further assumes that the dynamics of different reactions are explained by the reaction rates of different processes (Zuga and Cincu 2006). Reaction rates of activation, initiation, propagation, living polymer transfer, and the death of polymer chains are some of the most prominent processes parameter which must be defined.

Table 1. Modified mathematical model assumptions.

1. The CSTR comprises the liquid, gel, and solid phases.

2. Reactions occur within the catalyst liquid phase.

3. All phases are at controllable conditions.

4. There are negligible radial temperatures and concentration gradients in the CSTR.

5. The liquid phase is composed of VCM and $\mathrm{Hg}$.

6. The dynamics of reactions are represented by the rate of reaction rates of activation, initiation, propagation, the transfer of living polymers and the death of polymer chains.

CSTR $=$ continuous stirred tank reactor; $V C M=$ vinyl chloride monomer; $\mathrm{Hg}=$ mercury

\section{Reaction Kinetics}

When the reaction kinetics were analyzed, the rate of reaction while using the catalyst, involved five main mechanisms. These five mechanisms include rates of activation, initiation, and/or propagation; the transfer of living polymers; and the death of polymer chains. These steps, which are included in the reaction, involve mass and heat transfer, the diffusion of reactants from the bulk of VCM, and activation using a $\mathrm{Hg}$ catalyst flow rate inside process (Maezawa et al. 2004). All of these steps can significantly influence the overall reaction and mathematical model design for the CSTR process [Fig. 1]. 


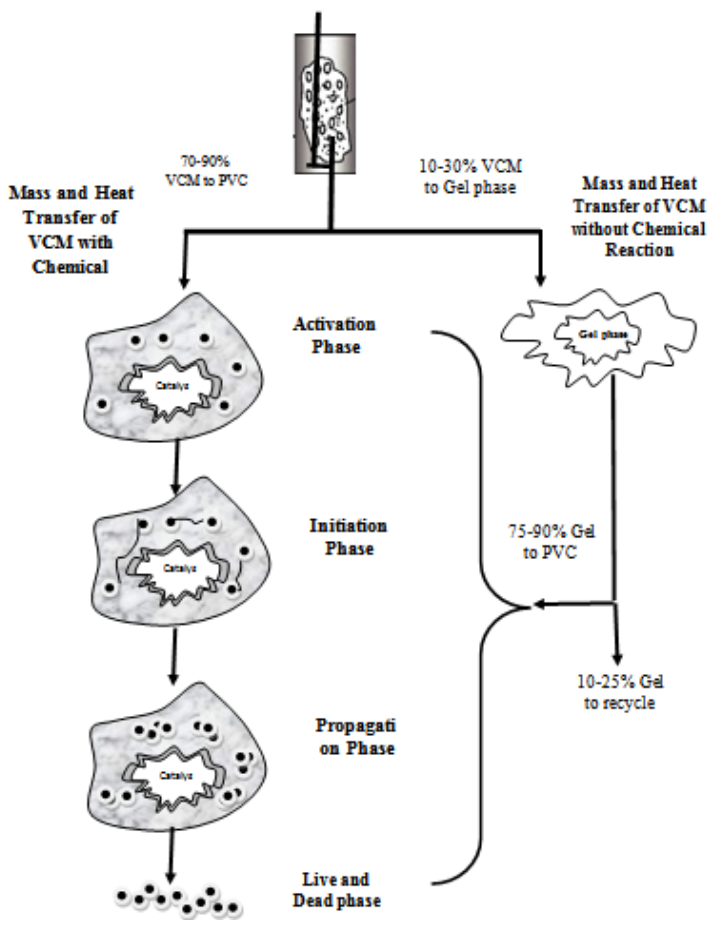

Figure 1. The Mechanism of the Chemical Reaction.

\section{Kinetic Reaction}

The kinetic reaction includes five mechanisms of the free radical method:

1. Rate of activation to activate two free radical alkyl groups [Eqn. 1]

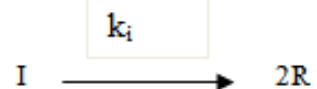

2. Rate of initiation of VCM

$$
\mathrm{R}+\mathrm{H}_{2} \mathrm{C}=\mathrm{CHCl} \stackrel{k_{\text {in }}}{\rightarrow} \mathrm{R}-\mathrm{CH}_{2}-\mathrm{CHCl} .
$$

3. Rate of propagation to produce a radical-free chain of the units of the monomer

$$
\mathrm{R}-\mathrm{CH}_{2}-\mathrm{CHCl} .+n\left(\mathrm{H}_{2} \mathrm{C}=\mathrm{CHCl}\right) \stackrel{k_{p}}{\rightarrow} \mathrm{R}-\left(\mathrm{H}_{2} \mathrm{C}=\mathrm{CHCl}\right)_{n}-\mathrm{CH}_{2}-\mathrm{CHCl} \text {. }
$$

4. Rate of the living polymer to transfer to the monomer

$$
\begin{gathered}
R-\left(\mathrm{H}_{2} \mathrm{C}=\mathrm{CHCl}\right)_{n}-\mathrm{CH}_{2}-\mathrm{CHCl} .+\mathrm{H}_{2} \mathrm{C}=\mathrm{CHCl} \stackrel{k_{\text {live }}}{\longrightarrow} \quad \mathrm{R}-\left(\mathrm{H}_{2} \mathrm{C}=\mathrm{CHCl}\right)_{n}-\mathrm{CH}_{2}-\mathrm{CH}_{2} \mathrm{Cl}+ \\
\mathrm{H}_{2} \mathrm{C}=\mathrm{CCl} \ldots \ldots .
\end{gathered}
$$

5. Rate of death in the live polymer to stop the propagation and life of polymer chains

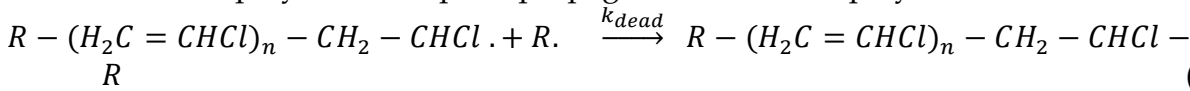

6. From Equations 1-5, the overall rate of reaction $\left(r_{a}\right)$ can be determined by the following Eqn. 6 :

$$
\mathrm{I}+n\left(\mathrm{H}_{2} \mathrm{C}=\mathrm{CHCl}\right) \stackrel{k n}{\rightarrow} \mathrm{R}-\left(\mathrm{H}_{2} \mathrm{C}=\mathrm{CHCl}\right)_{n}-\mathrm{CH}_{2}-\mathrm{CHCl}-\mathrm{R} \ldots \ldots \ldots
$$


$r_{a}=-k n\left[c(I) C_{A i}\right]$

Where,

$$
\begin{aligned}
& k n=\operatorname{Aerexp}\left(\frac{-E a}{R T}\right) \\
& \mathrm{E}_{\mathrm{G}}=\text { activation energy } \\
& \text { Aer }=\text { arrhenius number } \\
& \mathrm{R}=\text { gas constant, ie. } 8.314 \mathrm{~kJ} / \mathrm{Kmol} . \mathrm{k} \\
& \mathrm{T}=\text { temperature, ie. }{ }^{\circ} \mathrm{K}
\end{aligned}
$$

\section{CSTR Reactor Modeling}

According to Balakrishnam et al. (2005), the main reaction process within the CSTR contains several steps, including the three major steps which are incorporated in this process:

1. Heat and mass conversion of VCM from a liquid phase directly to the solid phase of PVC through a chemical reaction.

2. Mass and heat transformation of VCM from a liquid phase directly to the gel phase of PVC without a chemical reaction.

3. Mass and heat transfer of VCM from a gel phase to a solid phase of PVC through a chemical reaction.

\section{Mass and Heat Transfer of VCM from a Liquid Phase Directly to a Solid Phase of PVC with a Chemical Reaction}

In this state, 70-90\% of VCM transfers directly to the PVC. Mass and heat transfers with a chemical reaction represent five rates of reactions (Eqns. 1-7) and are represented in Eqns. 8 and 9, respectively.

$$
\begin{gathered}
\mathrm{C}_{\mathrm{Ai}}-\mathrm{C}_{\mathrm{Ao}}+\mathrm{r}_{\mathrm{a}} \mathrm{A} \rho_{\text {cat }}=\frac{\mathrm{v}}{\mathrm{F}_{\mathrm{Ai}}} \frac{\mathrm{dC}_{\mathrm{Ao}}}{\mathrm{dt}} \\
\mathrm{M}_{\mathrm{Ai}} \mathrm{C}_{\mathrm{p}}\left(\mathrm{T}_{\mathrm{i}}-\mathrm{T}_{\mathrm{o}}\right)+\mathrm{r}_{\mathrm{a}} \Delta \mathrm{H}_{\mathrm{r}} A \mathrm{Aw}_{\mathrm{cat}} \frac{\rho_{\mathrm{Ai}} \mathrm{F}_{\mathrm{Ai}}}{\mathrm{mw}_{\mathrm{Ai}}}= \\
\frac{\rho_{\mathrm{Ai}} \mathrm{VC}_{\mathrm{p}}}{\mathrm{mw}_{\mathrm{Ai}}} \frac{\mathrm{dT}_{\mathrm{o}}}{\mathrm{dt}}
\end{gathered}
$$

\section{Mass and Heat Transfer of VCM from a Liquid Phase Directly to a Gel Phase of PVC without a Chemical Reaction}

About $10-30 \%$ of VCM transfers to a gel phase.
Mass and heat transfer without chemical reactions are represented in Eqns. 10 and 11, respectively.

$$
\begin{array}{r}
\mathrm{k}_{\mathrm{lg}}\left(\mathrm{C}_{\mathrm{Ai}}-\mathrm{C}_{\mathrm{Ag}}\right)=\frac{\mathrm{dC}_{\mathrm{Ag}}}{\mathrm{dt}} \\
\mathrm{M}_{\mathrm{Ai}} \mathrm{C}_{\mathrm{p}}\left(\mathrm{T}_{\mathrm{i}}-\mathrm{T}_{\mathrm{g}}\right)=\frac{\rho_{A} V \mathrm{C}_{\mathrm{p}}}{\mathrm{mw}_{A i}} \frac{\mathrm{dT}_{\mathrm{g}}}{\mathrm{dt}}
\end{array}
$$

\section{Mass and Heat Transfer of the Gel Phase of VCM to the Solid Phase of PVC through a Chemical Reaction}

In this state, $75-90 \%$ of the VCM from a gel phase transfers directly to the PVC. Mass and heat transfers via a chemical reaction representing the five rates of reactions [Eqns. 1-7] are represented in Eqns. 12 and 13, respectively.

$$
\begin{gathered}
\mathrm{k}_{\mathrm{gs}}\left(\mathrm{C}_{\mathrm{Ag}}-\mathrm{C}_{\mathrm{Ao}}\right)+\mathrm{r}_{\mathrm{a}} A \rho_{\text {cat }}=\frac{\mathrm{v}}{\mathrm{F}_{\mathrm{Ai}}} \frac{\mathrm{dC}_{\mathrm{Ao}}}{\mathrm{dt}} \\
\mathrm{M}_{\mathrm{Ai}} \mathrm{C}_{\mathrm{p}}\left(\mathrm{T}_{\mathrm{g}}-\mathrm{T}_{\mathrm{o}}\right)+\mathrm{r}_{\mathrm{a}} \Delta \mathrm{H}_{\mathrm{r}} A m w_{c a t} \\
\frac{\rho_{\mathrm{Ai}} \mathrm{F}_{\mathrm{Ai}}}{\mathrm{mw_{Ai }}}=\frac{\rho_{\mathrm{A}} \mathrm{VC}_{\mathrm{p}}}{\mathrm{mw}_{\mathrm{Ai}}} \frac{\mathrm{dT}_{\mathrm{o}}}{\mathrm{dt}}
\end{gathered}
$$

\section{Model Solution and Analysis}

Equations 1-13 represent a previously revealed process model which encapsulates the parameter values included in Table 2 . The differential algebraic equation (DAE) solver of MATLAB software (The MathWorks, Inc., Natick, Massachusetts, USA) was used to determine values. In addition to the DAE, the modified fourth order of the Runge-Kutta method's variable step size was also incorporated. The operating parameters as well as physical constants were taken into account [Table 2] and deployed in a mathematical model system.

Simulation of the process was carried out to determine the impacts of the velocity of VCM flow rate on temperature and concentration reactions in the model. The simulation makes use of variable time and evaluates the concentration and temperature of the intermediate gel state. For different phases of the system, the simulation results will be described in the following section of the paper.

The effect of the VCM flow rate on the concentration in the process with respect to time 
Table 2. Physical constants and operating parameters for the mathematical model system.

$\begin{array}{cl}A= & 6.15 \mathrm{~m}^{2} \\ A e r & 3.12 \times 10^{12} \mathrm{sec}^{-1} \\ \rho_{\text {cat }} & 13534 \mathrm{~kg} / \mathrm{m}^{3} \\ \mathrm{~V} & 75 \mathrm{~m}^{3} \\ \mathrm{C}_{\mathrm{p}} & 1050 \mathrm{~J} / \mathrm{kg} \cdot \mathrm{k} \\ \mathrm{T}_{\mathrm{i}} & 35^{\circ} \mathrm{C} \\ \mathrm{T}_{\mathrm{g}} & 55^{\circ} \mathrm{C} \\ \mathrm{T}_{\mathrm{o}} & 63{ }^{\circ} \mathrm{C} \\ \Delta \mathrm{H}_{\mathrm{r}} & 91.6 \mathrm{~kJ} / \mathrm{mol} \\ \mathrm{Ea} & 107033 \mathrm{~kJ} / \mathrm{mol} \\ \mathrm{mw} \mathrm{w}_{\text {cat }} & 200.6 \mathrm{~kg} / \mathrm{Kmol} \\ \rho_{\mathrm{Ai}} & 860 \mathrm{~kg} / \mathrm{m}^{3} \\ \mathrm{mw}_{\mathrm{Ai}} & 62.5 \mathrm{~kg} / \mathrm{mol} \\ \mathrm{k}_{\mathrm{lg}} & 0.57<\frac{\mathrm{k}_{\mathrm{lg}}}{\mathrm{k}_{\mathrm{gs}}} \\ \mathrm{k}_{\mathrm{gs}} & 100 \% \\ C_{V C M} & 2.889 \times 10^{5} \mathrm{sec}^{-1} \\ \mathrm{k}_{\mathrm{i}} & 5.779 \times 10^{5} \mathrm{sec}^{-1} \\ \mathrm{k}_{\text {in }} & 5.779 \times 10^{5} \mathrm{sec}^{-1} \\ \mathrm{k}_{\mathrm{p}} & 1.506 \times 10^{2} \mathrm{sec}^{-1} \\ \mathrm{k}_{\text {live }} & 3.125 \times 10^{2} \mathrm{sec}^{-1} \\ \mathrm{k}_{\text {dead }} & \end{array}$

and the conversion of the reaction is proportional to the flow rate of VCM [Fig. 2]. The conversion is equal to $7.2 \%$ when the VCM flow rate is $0.004 \mathrm{~m}^{3} /$ second at 2.16 hours. The conversion is equal to $12 \%$ when the VCM flow rate is 0.02 $\mathrm{m}^{3} /$ second at 1.634 hours, and the conversion is equal to $21.3 \%$ when the VCM flow rate is 0.05 $\mathrm{m}^{3} /$ second at 0.56 hours. PVC production is proportional to the VCM flow rate [Fig. 2].

Gel concentration is inversley proportional to the VCM flow rate [Fig. 3], especially for the first three hours of the reaction due to about $90 \%$ of the VCM being transferred to PVC. Figure 3 shows two different VCM flow rates $\left(0.004 \mathrm{~m}^{3} /\right.$ second and 0.02 $\mathrm{m}^{3} /$ second) and their effects on the concentration of the gel phase. The concentration increases more for $\mathrm{VCM}=0.004 \mathrm{~m}^{3} /$ second as compared to the $\mathrm{VCM}=0.02 \mathrm{~m}^{3} / \mathrm{sec}$.

VCM consumption and the production of PVC and of gel phases increased with time [Fig. 4]. Concentrations of PVC and the gel phase depend on the VCM flow rate and catalyst flow rate [Figs. 2-4].

The temperature of the gel phase increased with time until it reaches the reaction temperature of the system [Fig. 5]. It was found that the temperature of the reaction decreased for the first 10 minutes of the reaction because a parallel reaction forms the gel phase and absorbs the energy at the beginning of reaction. At that point, the overall reaction temperature of the system increased until it reached one temperature which represents the entire system [Fig. 6]. Figure 7 shows a comparison between the gel phase and reaction temperatures at the first ten minutes.

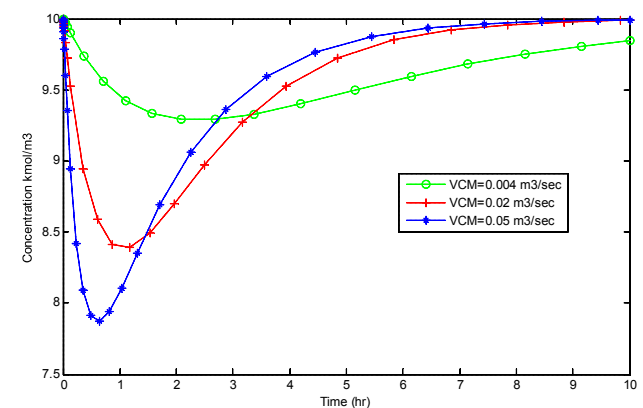

Figure 2. Effects of VCM flow rate in the liquid and solid phases with variable time for reaction concentration. 


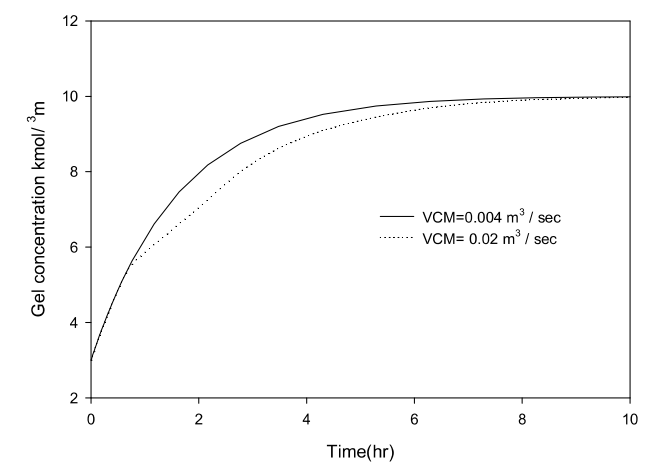

Figure 3. Effect of VCM flow rate on the gel concentration changes with the time.

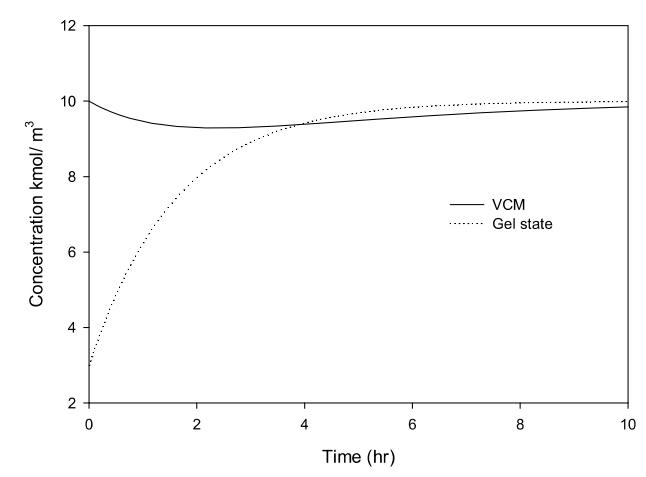

Figure 4. Variation in concentrations of VCM and gel with the time.

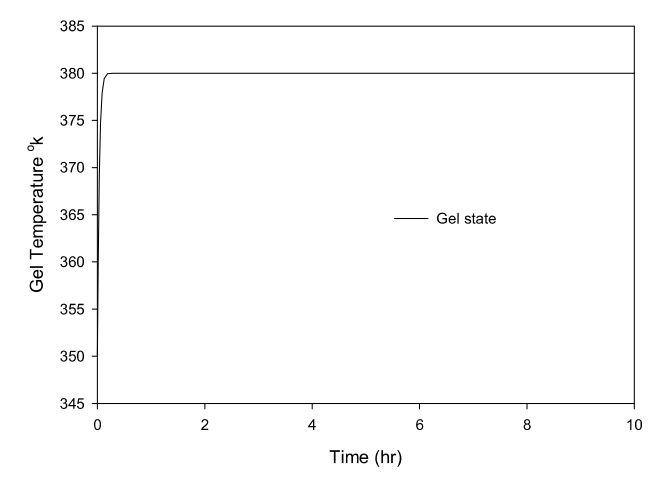

Figure 5. Variation in gel temperature with the time.

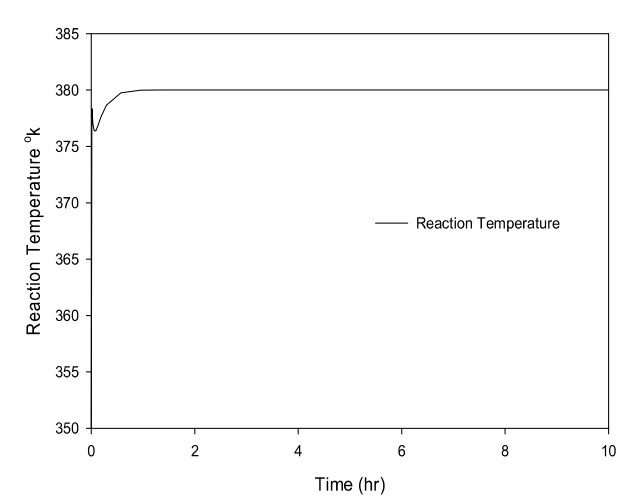

Figure 6. Variation in reaction temperature with the time.

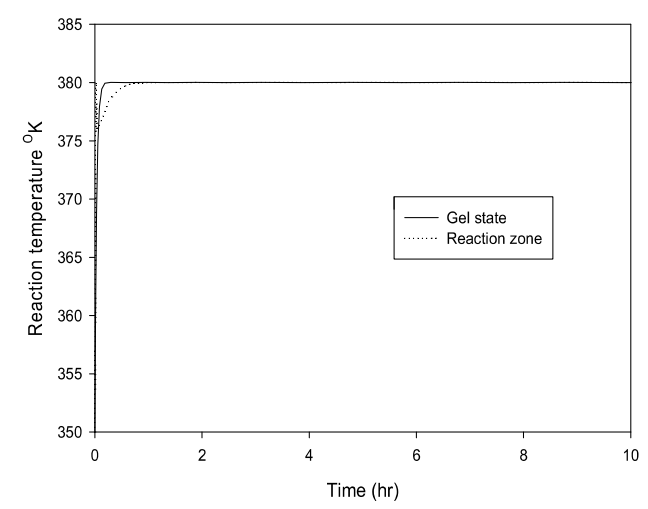

Figure 7. Variation in reaction and gel temperatures with the time.

\section{Model Validation Study}

The accuracy and reliability of the steady state behavior of this proposed mathematical model can be seen by making a comparison with the published experimental data presented by Chattopadhyay and Madras (2002). Figures 8 and 9 illustrate the concentration and reaction temperature of PVC, respectively. The condition related to ten different samples presented by Chattopadhyay and Madras (2002) are compared in the two figures. In Figs. 8 and 9, for instance, the first sample differs by only about $0.2 \mathrm{kmol} / \mathrm{m} 3$ of concentration and $3.2^{\circ} \mathrm{K}$ of reaction temperature with respect to the actual plant results, respectively. In Fig. 10, the comparison between experimental data and model predictions is given for a typical polymerization. The comparison was performed in the presence of all rates of reaction. Data illustrated by both figures show good agreement between the results obtained from the proposed model and the actual experimental results. 


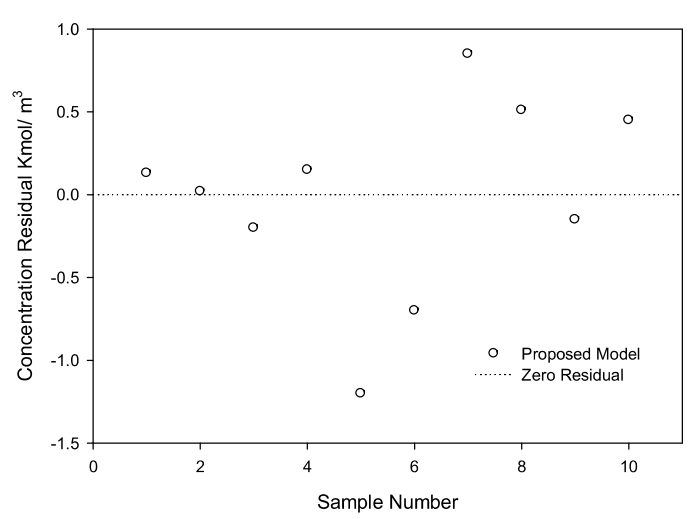

Figure 8. Actual Plant versus new Model Predicted Concentration Values.

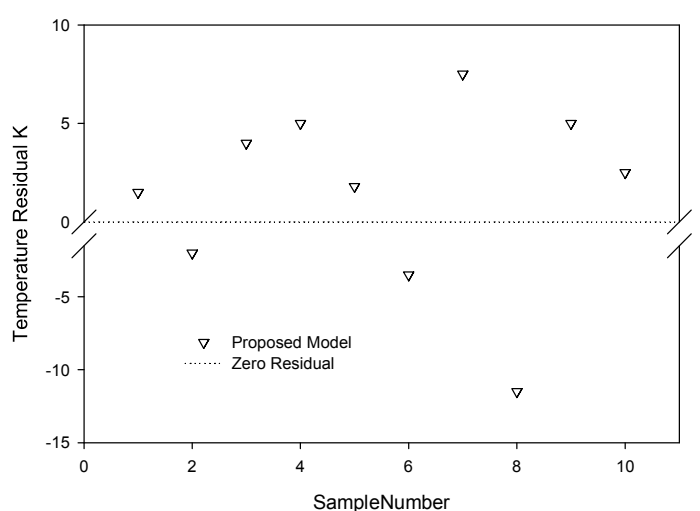

Figure 9. Actual versus Model Predicted Reaction Temperature.

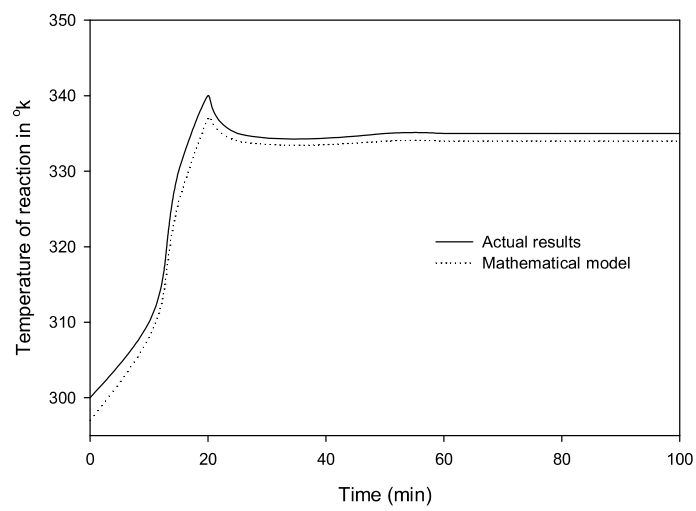

Figure 10. Comparison between Experimental Measurements and Theoretical Mathematical Model Predictions on Reaction Temperature.

\section{Conclusions}

A new dynamic mathematical model for a threephase structure model has been proposed in this research. The proposed model takes into account the presence of particles contributing to the reaction in the liquid, gel, and solid phases. These phases depend on catalyst feed and volumetric flow rates of VCM. In addition to this, mass and heat transfers between the two phases were found, with the solid and gel phases considered in calculations of both heat and mass transfer. According to observations, this model can be conveniently used as a predictive tool in order to determine and examine the impacts of hydrodynamics, and operating and kinetic parameters on the performance of reactors as well as on the properties of PVC.

\section{References}

Ambrozek B, Nastaj J, Gabrus E (2012), Modeling of adsorptive drying of N-PVC. Drying Technology: An International Journal 30: 10.

Balakrishnan B, Kumar DS, Yoshida Y, Jayakrishnan A (2005), Chemical modification of PVC using poly ethylene glycol to improve blood compatibility. Biomaterials and Artificial Organs, 18(32): 6335-6342.

Blazevska-Gilev J, Spasesk D (2010), Formal kinetic analysis of PVC thermal degradation. Journal of the University of Chemical Technology and Metallurgy 45(3): 251-254.

Chattopadhyay S, Madras G (2002), Degradation of PVC properties. Polymer Degradation and Stability 71: 273-278.

Chavadej S, Phuaphromyod P, Gulari E, Rangsunvigit P, Sreethawong TM (2008), Photocatalytic degradation of 2-PVC by using $\mathrm{Pt} / \mathrm{TiO} 2$ prepared by microemulsion technique, Chemical Engineering Journal 137(3): 489-495.

Cohan GF (1975), Industrial preparation of polyvinyl chloride. Environmental Health Perspectives 11: 53-57.

Field MA (1973), Predication of optimum temperature profiles for vinyl chloride polymerization using mathematical model. ICI Internal Report.

Ibrahem SA (2012), Chemical reaction engineering and design by using MATLAB software. Saarbrücken, LAP Lambert Academic Publishing $\mathrm{AG}$ and Co.

Kamo T, Yamamoto Y, Miki K, Sato Y (2012), Conversion of waste PVC to useful chemicals, 
Report of National Institute for Resources and Environment.

Kiparissides C, Achilas DS, Chatzi E (1994), Dynamic simulation of primary particle size distribution in vinyl chloride polymerization. Journal of Applied Polymer Science 54: 1423-1438 .

Lathia JD, El-Sherif D, Wheatley MA (2004), Surface modification of polymeric contrast agents for cancer targeting. Pharmaceutical Engineering 23(6): 142-143.

Lăzăroaie C, Rusen E, Mărculescu B, Zecheru T, Hubcă G (2010), Chemical modification of PVC polymer matrices with special properties. UPB Science Bulletin 72(2): 127-140.
Maezawa Y, Tezuka F, Inoue Y (2004), Study and Evaluation of Kinetic Analysis Of PVC Thermal Degradation. Polymer Degradation and Stability 81(2): 187-196.

Scott DS, Czernik SR, Radlein DS (1990), Thermal analysis of PVC in the environment. Energy and Fuels 4(4): 407-411.

Zuga D, Cincu C (2006), Polymer composites by reclaiming rubber wastes resulting from finishing the rubberized rolls used in printing industry. UPB Science Bulletin, Series B, 68(1): 25-30. 